\title{
Assessment of Antiretroviral Treatment Adherence among Children Attending Care at a Tertiary Hospital in Southeastern Nigeria
}

\author{
Cletus Akahara, ${ }^{1}$ Emeka Nwolisa, ${ }^{1}$ Kelechi Odinaka, ${ }^{1}$ and Seline Okolo ${ }^{2}$ \\ ${ }^{1}$ Department of Paediatrics, Federal Medical Centre, Owerri, Imo State, Nigeria \\ ${ }^{2}$ Department of Paediatrics, University of Jos Teaching Hospital, Plateau State, Nigeria \\ Correspondence should be addressed to Kelechi Odinaka; kellymed112@yahoo.com
}

Received 31 August 2016; Revised 8 December 2016; Accepted 15 January 2017; Published 5 February 2017

Academic Editor: Marcel Tanner

Copyright (c) 2017 Cletus Akahara et al. This is an open access article distributed under the Creative Commons Attribution License, which permits unrestricted use, distribution, and reproduction in any medium, provided the original work is properly cited.

\begin{abstract}
Background. Adherence is the strongest predictor of successful treatment outcome among children infected with HIV. Our aim was to assess the antiretroviral drugs adherence status of HIV-infected children attending care at a tertiary hospital in Southeastern Nigeria. Method. The study involved a cross-sectional survey of 210 HIV-infected children attending care at a tertiary hospital in Southeastern Nigeria using self-report method of assessment. Optimal ART adherence is defined as patient taking not missing more than 1 dose of combined antiretroviral therapy medication in the preceding 2 weeks prior to the study. Result. A majority of the subjects 191 (91\%) had good adherence. There was a significant relationship between adherence and patient educational level $(p=0.004)$, duration of treatment $(p=0.001)$, drug administrator $(p=0.005)$, and orphan status $(p=0.001)$. The motivating factor for adherence was "not falling sick as before" while stigma was the most discouraging factor. Conclusion. The adherence level in this study was good. Stigma was an important reason given by patient/caregivers for nonadherence. There is need for concerted effort in addressing this barrier to improve adherence and prevent the emergence of drug resistance and treatment failure.
\end{abstract}

\section{Introduction}

Human Immunodeficiency Virus (HIV) infection and the resultant Acquired Immunodeficiency Syndrome (AIDS) have remained of significant public health concern especially in sub-Saharan Africa where they still contribute significantly to childhood morbidity and mortality [1]. There are yet no curative drugs but the use of combined antiretroviral therapy (cART) has ensured better outcomes. cART consists of the use of mostly three antiretroviral agents and good adherence is the most important determinant of success and positive outcome [2].

With regard to antiretroviral therapy (ART), an adherence level of $95 \%$ or more is required in order to obtain successful outcome [3]. Suboptimal adherence can lead to incomplete viral suppression, emergence of resistant viral strains, and treatment failure. Paediatric adherence relies on the child and his/her caregiver and as such is especially challenging [4-10].
Given that adherence is the strongest predictor of successful treatment outcome [2], a clearer understanding of adherence barriers is very crucial in a bid to develop measures to support and sustain patient's adherence in the clinical care of HIV-infected children.

Several methods have been used to measure adherence and they include Therapeutic Drug Monitoring (TDM), Directly Observed Therapy (DOT), Pill counts, Medication Event Monitoring System (MEMS), and self-report.

In the self-report method, the patient or caregiver in the case of children gives information on how the drugs are taken and reports on missed doses. The method hinges on the client providing true and accurate information.

This study is set to assess the antiretroviral drugs adherence status as well as identify reasons influencing adherence of HIV-infected children attending the Paediatric HIV Disease Clinic of the Federal Medical Centre, Owerri, Imo State, Nigeria. 


\section{Method}

The study was conducted at the Paediatric HIV Clinic of the Federal Medical Centre, Owerri, Imo State, Nigeria. The centre is one of the major HIV/AIDS treatment centres in the South East geographical region of Nigeria.

2.1. Ethical Approval. The Research and Ethical Committee of Federal Medical Centre, Owerri, gave ethical clearance for the study. Informed written consent was obtained from the caregivers and assent from children older than 10 years.

\section{Inclusion Criteria}

(1) HIV-infected children aged 10-180 months

(2) HIV-infected children on cART for at least 4 months

(3) Informed consent from caregiver

\section{Exclusion Criteria}

(1) Subjects above 15 years

(2) HIV-infected children yet to commence cART

(3) Subjects whose caregiver did not give informed consent

2.2. Study Duration. The study was carried out over a 4month period (September to December 2013).

2.3. Data Collection. A pretested questionnaire was used for data collection. The information sought included the caregiver's related factors such as age, educational level, occupation, relationship to subject, and treatment duration. Also the patient's related factors like age, gender, education, orphan status, and missed doses were sought.

Adherence was determined using the self-reporting method. Adolescent patients and their parents/caregivers (for the younger subjects below 10 years of age) were asked to recall how many times they missed taking drugs as prescribed in the two weeks preceding the study. Patients were classified as having good adherence if they scored $\geq 95 \%$ (not missing more than 1 dose).

2.4. Data Analysis. The data from the questionnaire were sorted, coded, and entered into the computer and analyzed using the SPSS version 20.0, Chicago, Illinois, USA. The data was further subjected to descriptive and analytical statistics to generate frequencies and percentages. Chi square was used to test for association between two categorical variables. $p$ value $<0.005$ is considered to be statistically significant.

\section{Results}

A total of 210 patients who met the inclusion criteria were enrolled in the study. There were 108 males and 102 females giving a male: female ratio of $1.05: 1$.

The sociodemographic characteristic of patients studied is shown in Table 1.136 (64.8\%) of the studied patients were aged 12-119 months while 106 (50.5\%) of the studied patients had been on cART between 12 and 35 months. 146 (69.5\%) had their drugs administered by their biological parents. While 64 patients (30.5\%) were single orphans and $22(10.5 \%)$ were dual orphans.

191 (91\%) had good adherence. Adherence in female patients was $92 \%$ while it was $90 \%$ in the male subjects. The difference though was not statistically significant $(p=0.554)$. There was a significant relationship between adherence and patient educational level ( $p=0.004)$, duration of treatment $(p=0.001)$, drug administrator $(p=0.005)$, and orphan status $(p=0.001)$.

Table 2 shows the reasons for good adherence. The major reason for good adherence was the patient was not as sick as before. Table 3 shows the reasons for poor adherence. These information pieces were given by the patient.

\section{Discussion}

The adherence rate among patients in this study was $91 \%$. This corroborates the study of Iroha et al. [11] and MukhtarYola et al. [12] but differed from the study of Ugwu and Eneh [6] in Port-Harcourt, Nigeria. These studies all used the self-reporting method in assessment of adherence. Whereas our study assessed adherence by recall over the previous two weeks, Ugwu and Eneh [6] assessed recall over a one-month period. The lower adherence levels reported by Ugwu and Eneh [6] may be associated with recall bias against a shorter period (two weeks) used in the present study.

The percentage of patients being adherent was observed to differ across age groups. This pattern was also observed by Zubayr et al. [13] and Iroha et al. [11]. The pattern of decreasing adherence with increasing age agrees with reports from Kampala [14], Ethiopia [15], and Cape Town [16] which documented a worsening ART nonadherence with increasing patient's age. This is natural as children do not like taking drugs every day of their life and they also do not like to appear different from their peers.

Despite sociocultural preference for male children by the Igbos of Southeastern Nigeria, our study observed that adherence was higher in females than males, although the difference was not significant. This observation corroborates earlier reports by Ugwu and Eneh [6] and Zubayr et al. [13] that found no significant association between the gender of the child and ART adherence. This implies that gender may not influence ART adherence.

Adherence was higher in patients whose biological parents administered the drugs. The relationship between drug administrator and adherence was statistically significant. This study finding is in tandem with the study of Zubayr et al. [13]. This may not be surprising as the parents were responsible for most of their children's plight; they appreciate the benefits of ART and, therefore, will take every step to motivate their children to adhere to medication.

The most common reason given by respondents for ART adherence in this study was "not falling sick as before." This is evidenced by reduced hospital visits and admissions, improved patient's weight, and not missing schools like in the past prior to commencing treatment. Similar reason has also been reported by other studies [11, 12]. Other factors which enhanced adherence included provision of appropriate 
TABLE 1: Sociodemographic characteristics of the children studied $(n=210)$.

\begin{tabular}{|c|c|c|c|c|}
\hline Characteristics & $\begin{array}{l}\text { All patients } \\
(n=210)\end{array}$ & $\begin{array}{l}\text { Adherent patients } \\
\quad(n=191)\end{array}$ & $\begin{array}{l}\text { Nonadherent patients } \\
\qquad(n=19)\end{array}$ & $p$ value \\
\hline \multicolumn{5}{|l|}{ Age (months) } \\
\hline$<12$ & $3(1.4 \%)$ & $3(1.6 \%)$ & $0(0 \%)$ & \multirow{4}{*}{0.110} \\
\hline $12-59$ & $59(28.1 \%)$ & $57(29.8 \%)$ & $2(10.5 \%)$ & \\
\hline $60-119$ & $77(36.7 \%)$ & $71(37.2 \%)$ & $6(31.6 \%)$ & \\
\hline $120-180$ & $71(33.8 \%)$ & $60(31.4 \%)$ & $11(57.9 \%)$ & \\
\hline \multicolumn{5}{|l|}{ Gender } \\
\hline Male & $108(51.4 \%)$ & $97(50.8 \%)$ & $11(57.9 \%)$ & \multirow{2}{*}{0.750} \\
\hline Female & $102(48.6 \%)$ & $94(49.2 \%)$ & $8(42.1 \%)$ & \\
\hline \multicolumn{5}{|l|}{ Educational level } \\
\hline Not of school age & $65(31.0 \%)$ & $64(33.5 \%)$ & $1(5.3 \%)$ & \multirow{3}{*}{$0.004^{*}$} \\
\hline Primary & $85(40.5 \%)$ & $78(40.8 \%)$ & $7(36.8 \%)$ & \\
\hline Secondary & $60(28.5 \%)$ & $49(25.7 \%)$ & $11(57.9 \%)$ & \\
\hline \multicolumn{5}{|c|}{ Treatment duration (months) } \\
\hline$<12$ & $12(5.7 \%)$ & $12(6.3 \%)$ & $0(0 \%)$ & \multirow{4}{*}{$0.001^{*}$} \\
\hline $12-35$ & $106(50.5 \%)$ & $103(53.9 \%)$ & $3(15.8 \%)$ & \\
\hline $36-59$ & $68(32.4 \%)$ & $61(31.9 \%)$ & $7(36.8 \%)$ & \\
\hline$>60$ & $24(11.4 \%)$ & $15(7.9 \%)$ & $9(47.4 \%)$ & \\
\hline \multicolumn{5}{|c|}{ Who administers the medication } \\
\hline Self (age $\geq 10$ years) & $26(12.4 \%)$ & $19(9.9 \%)$ & $7(36.8 \%)$ & \multirow{4}{*}{$0.005^{*}$} \\
\hline Biological parent & $146(69.5 \%)$ & $138(72.3 \%)$ & $8(42.1 \%)$ & \\
\hline Biological grandparent & $31(14.8 \%)$ & $28(14.7 \%)$ & $3(15.8 \%)$ & \\
\hline Others & $7(3.3 \%)$ & $6(3.1 \%)$ & $1(5.3 \%)$ & \\
\hline \multicolumn{5}{|l|}{ Orphan status } \\
\hline Both parents alive & $124(59.0 \%)$ & $117(61.3 \%)$ & $7(36.8 \%)$ & \multirow{3}{*}{$0.001^{*}$} \\
\hline One parent alive & $64(30.5 \%)$ & $60(31.4 \%)$ & $4(21.1 \%)$ & \\
\hline Both parents dead & $22(10.5 \%)$ & $14(7.3 \%)$ & $8(42.1 \%)$ & \\
\hline
\end{tabular}

* Statistically significant.

TABLE 2: Reasons given by patients/caregivers for good adherence.

\begin{tabular}{lcc}
\hline Reasons for adherence & $\begin{array}{c}\text { Number* } \\
(n=191)^{*}\end{array}$ & Percent* \\
\hline No longer as sick as before & 178 & $(93 \%)$ \\
Caregiver had good information & 143 & $(75 \%)$ \\
Availability of nutritional support & 70 & $(37 \%)$ \\
Seeks to stay alive & 46 & $(24 \%)$ \\
Influence of support group in the centre & 36 & $(19 \%)$ \\
\hline
\end{tabular}

${ }^{*}$ Some respondents gave multiple reasons.

information and nutritional support which in our centre was by way of provision of Plumpy nuts, and existence of an active patient driven support group has also been documented by other studies [17-19].

Stigmatization was the strongest factor for nonadherence in the present study. Because of the strong influence of stigmatization, health education and information should be increased and sustained through the use of social media, religious gatherings, and even town criers where available
TABLE 3: Reasons given by patients/caregivers for poor adherence.

\begin{tabular}{lcc}
\hline Reasons for poor adherence & $\begin{array}{c}\text { Number }^{*} \\
(n=19)\end{array}$ & Percent* \\
\hline Stigma & 16 & $(84 \%)$ \\
Forgetfulness & 6 & $(32 \%)$ \\
Caregiver not well & 5 & $(26 \%)$ \\
Did not know drugs were daily & 4 & $(21 \%)$ \\
Away from home & 4 & $(21 \%)$ \\
Patient was sick & 4 & $(21 \%)$ \\
Feeling healthy & 3 & $(16 \%)$ \\
Unpleasant drug side effects & 2 & $(11 \%)$ \\
Nonavailability of food & 1 & $(5 \%)$ \\
\hline
\end{tabular}

${ }^{*}$ Some respondents gave multiple reasons. Subjects/caregivers who gave more reasons have lower adherence to medications.

(personal suggestion). This can positively influence the community acceptance of the disease thereby demystifying the associated stigma and increasing ART adherence. The barrier 
to adherence in this study is in contrast to the drug exhaustion at home as the main reason for nonadherence in some earlier studies $[11,12]$. The reason for the drug exhaustion at home was sharing with patient's ARV medication with other siblings [12]. Surprisingly, drug side effects were not a major barrier to effective ART adherence in the present study. This agrees with a study in Kampala [14] but differs from the study of Iroha et al. [11]. The reason for the observed difference is not known.

\section{Conclusion}

The adherence level in this study was good. Stigma was an important reason given by the patient for nonadherence. There is need for concerted effort in addressing this barrier to improve adherence and prevent emergence of drug resistance and treatment failure.

\section{Competing Interests}

The authors declare no conflict of interests.

\section{Acknowledgments}

The authors wish to acknowledge the immense support of the staff of the Paediatric HIV Clinic of the Federal Medical Centre, Owerri, Nigeria.

\section{References}

[1] WHO-HIV-AIDS: Fact Sheet No. 360, November 2014.

[2] N. Nabukeera-Barungi, "Factors affecting ART uptake, adherence and prevention of transmission among HIV positive children and adolescents in Uganda," Tech. Rep., USAID, 2007.

[3] D. L. Paterson, S. Swindells, J. Mohr et al., "Adherence to protease inhibitor therapy and outcomes in patients with HIVinfection," Annals of Internal Medicine, vol. 133, no. 1, pp. 21-30, 2000.

[4] Center for Disease Control and Prevention, "Evaluation of adherence to ART in children in Nigeria," AIDS, vol. 22, pp. 2371-2380, 2008.

[5] S. L. Marhefka, J. J. Farley, J. R. Rodrigue, L. L. Sandrik, J. W. Sleasman, and V. J. Tepper, "Clinical assessment of medication adherence among HIV-infected children: examination of the Treatment Interview Protocol (TIP)," AIDS Care-Psychological and Socio-Medical Aspects of AIDS/HIV, vol. 16, no. 3, pp. 323337,2004

[6] R. Ugwu and A. Eneh, "Factors influencing adherence to paediatric antiretroviral therapy in Portharcourt, South- South Nigeria," Pan African Medical Journal, vol. 16, article 30, 2013.

[7] R. Weigel, I. Makwiza, J. Nyirenda, D. Chiunguzeni, S. Phiri, and S. Theobald, "Supporting children to adhere to anti-retroviral therapy in urban Malawi: multi method insights," $B M C$ Pediatrics, vol. 9, article 45, 2009.

[8] C. A. Shah, "Adherence to High Activity Antiretrovial Therapy (HAART) in pediatric patients infected with HIV: issues and interventions," Indian Journal of Pediatrics, vol. 74, no. 1, pp. 5560, 2007.

[9] M. Goode, A. Mcmaugh, J. Crisp, S. Wales, and J. B. Ziegler, "Adherence issues in children and adolescents receiving highly active antiretroviral therapy," AIDS Care, vol. 15, no. 3, pp. 403408, 2003.

[10] M. A. Davies, A. Boulle, T. Fakir, J. Nuttall, and B. Elley, "Adherence to antiretroviral therapy in young children in Cape Town, South Africa, measured by medication return and caregiver self-report: a prospective cohort study," BMC Pediatrics, vol. 8, article 34, 12 pages, 2008.

[11] E. Iroha, C. I. Esezobor, C. Ezeaka, E. O. Temiye, and A. Akinsulie, "Adherence to antiretroviral therapy among HIVinfected children attending a donor-funded clinic at a tertiary hospital in Nigeria," African Journal of AIDS Research, vol. 9, no. 1, pp. 25-30, 2010.

[12] M. Mukhtar-Yola, S. Adeleke, D. Gwarzo, and Z. F. Ladan, "Preliminary investigation of adherence to antiretroviral therapy among children in Aminu Kano Teaching Hospital, Nigeria," African Journal of AIDS Research, vol. 5, no. 2, pp. 141-144, 2006.

[13] B. Zubayr, M. Ibrahim, J. Jumare et al., "Adherence to highly active antiretroviral therapy among HIV-infected children in Kano, Nigeria," Journal of Human Virology \& Retrovirology, vol. 2, no. 2, pp. 1-6, 2015.

[14] N. Nabukeera-Barungi, I. Kalyesubula, A. Kekitiinwa, J. Byakika-Tusiime, and P. Musoke, "Adherence to antiretroviral therapy in children attending Mulago Hospital, Kampala," Annals of Tropical Paediatrics, vol. 27, no. 2, pp. 123-131, 2007.

[15] S. Biadgilign, A. Deribew, A. Amberbir, and K. Deribe, "Adherence to highly active antiretroviral therapy and its correlates among HIV infected pediatric patients in Ethiopia," BMC Pediatrics, vol. 8, pp. 53-65, 2008.

[16] M.-A. Davies, A. Boulle, T. Fakir, J. Nuttall, and B. Eley, "Adherence to antiretroviral therapy in young children in Cape Town, South Africa, measured by medication return and caregiver self-report: a prospective cohort study," BMC Pediatrics, vol. 8, article 34, 2008.

[17] K. Peltzer, N. F.-D. Preez, S. Ramlagan, and J. Anderson, "Antiretroviral treatment adherence among HIV patients in KwaZulu-Natal, South Africa," BMC Public Health, vol. 10, article 111, 2010.

[18] G. L. Birbeck, E. Chomba, M. Kvalsund et al., "Antiretroviral adherence in rural Zambia: the first year of treatment availability," The American Journal of Tropical Medicine and Hygiene, vol. 80, no. 4, pp. 669-674, 2009.

[19] E. Wood and J. S. G. Montaner, "When to initiate HIV antiretroviral therapy: do benefits other than survival deserve greater attention?" Journal of Acquired Immune Deficiency Syndromes, vol. 45, no. 2, pp. 131-132, 2007. 


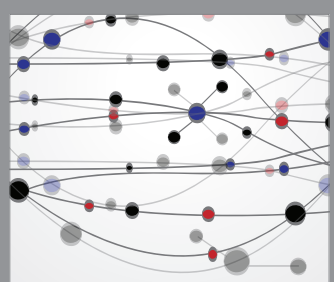

The Scientific World Journal
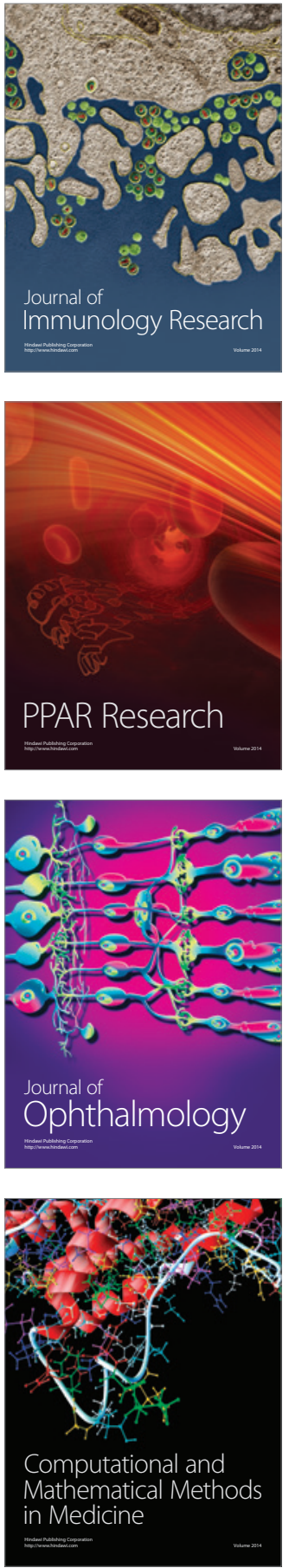

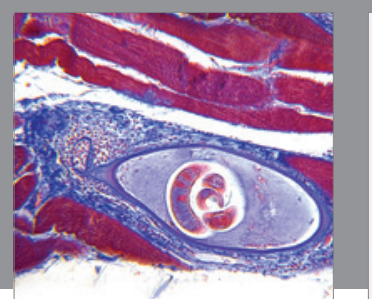

Gastroenterology Research and Practice


Disease Markers

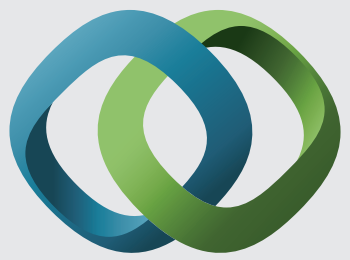

\section{Hindawi}

Submit your manuscripts at

https://www.hindawi.com
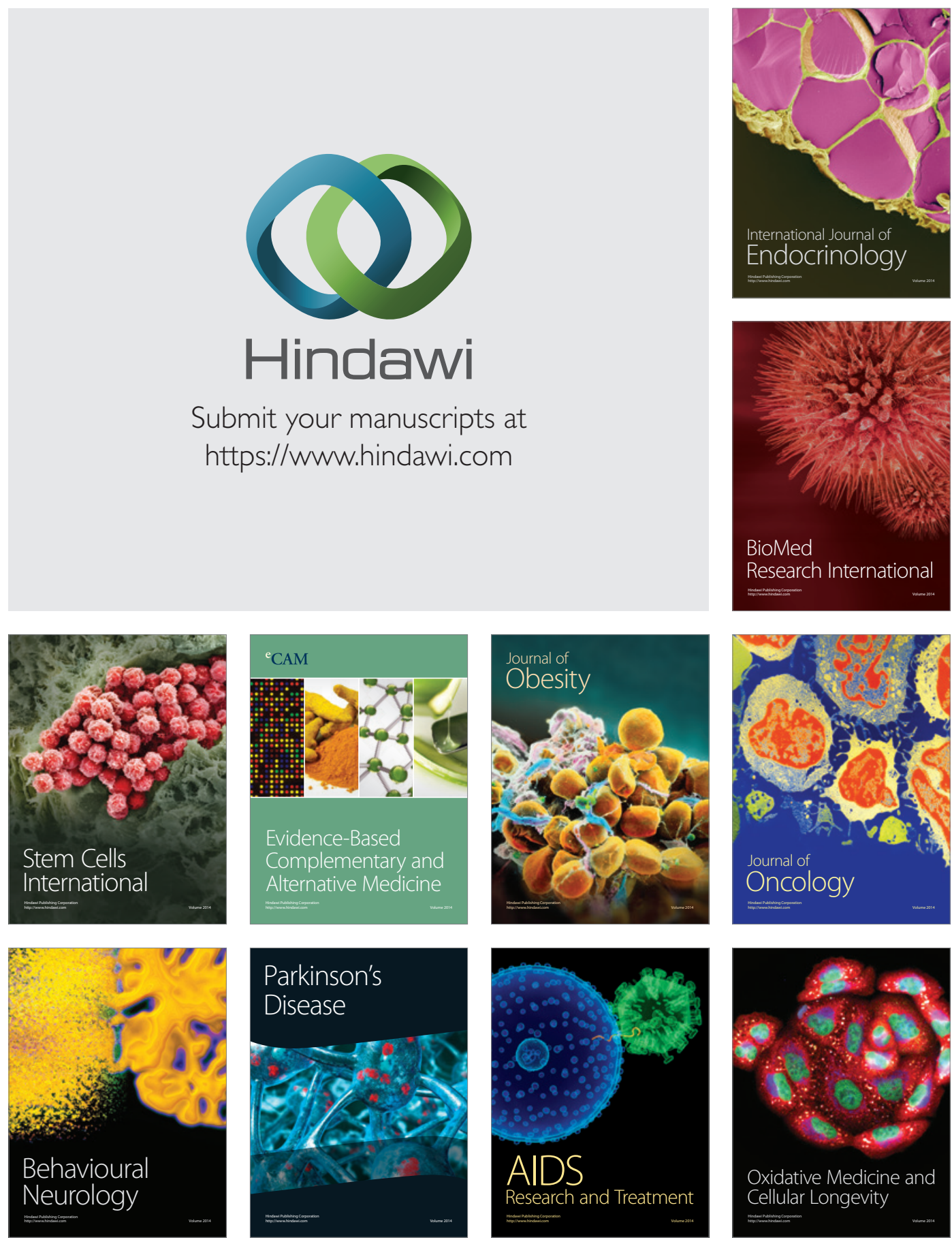